\title{
A meta-analysis of the impact of traffic-related air pollution on health and the factors affecting exposure
}

\author{
D. Lockhart, M. Vaganay, S. MacIntyre \& P. Joseph \\ School of the Built Environment and the Built Environment Research \\ Institute, Ulster University, UK
}

\begin{abstract}
Clean air is a basic requirement for health and well-being. One of the main sources of air pollution is traffic. It emits harmful pollutants including nitrogen dioxide and particulate matter. There is a large body of existing evidence regarding the public health impact of air pollution. A wide range of health problems including respiratory and cardiovascular illnesses have been found. The evidence in relation to the impact of traffic related air pollution is inconsistent therefore the aim of this paper is to provide clarity on the strength of evidence. In addition, the review will consider the impact of environmental and personal exposure factors. To identify relevant research, the database Science Direct was used along with a search strategy. This review found there is a large body of evidence in relation to air pollution from traffic, health impacts and environmental factors. Due to methodological limitations and the complexity of the interactions the strength of this evidence is mixed. Links to cardiovascular illnesses were considered the most significant. A number of environmental factors such as weather and built environment have significant impacts on traffic related air pollution levels. The review highlights the lack of comprehensive and robust evidence linking environmental factors, traffic related air pollution and health impacts. Future work should use appropriate methodologies to address these gaps.
\end{abstract}

Keywords: traffic related air pollution, nitrogen dioxide, particulate matter, health, exposure factors. 


\section{Introduction}

Ambient air pollution is a worldwide issues which impacts the health of the population. It is estimated that ambient air pollution caused 3.7 million deaths worldwide in 2012 [1]. In Europe, nine out of ten people who live in cities are exposed to levels of air pollution higher than recommended within the World Health Organisation Guidelines [2].

While there are a range of sources which impact on the levels of air pollution, road transport has been identified as one of the biggest contributors to ambient air quality. It emits two of the most widespread pollutants, nitrogen dioxide and particulate matter [3]. This review will focus on research completed on traffic related air pollution.

There has been a substantial amount of research regarding the public health impact of air pollution. Its effects have been linked to respiratory illnesses, cardiovascular illnesses and various other additional health problems.

\section{Methodology}

To identify relevant literature, an electronic search of a bibliographic database was conducted. The database chosen was Science Direct. The search was limited to peer reviewed journal articles, published in English. A number of key words were identified and used to form a search strategy. The search terms included a combination of key words incorporating the key themes: traffic related air pollution, health effects and exposure factors. The results were refined by limiting the articles to those published within the last five years.

To identify research on the health impacts, the following search term was used, "traffic related air pollution" AND "health effects". The initial search resulted in 855 unduplicated research papers. The search was refined again by limiting articles to relevant topics, this included air pollution, nitrogen dioxide concentration, particulate matter, cardiovascular, respiratory, birth weight and health effects. Limiting the topics reduced the number of articles to 254. After reviewing the abstracts, a further 219 were excluded for not specifically focusing on traffic related air pollution. The remaining 35 papers were critically reviewed as the first part of this systematic literature review.

A second search was completed to identify research papers which focused on the factors affecting the levels of air pollution that the population are exposed to. A combination of key words were used to identify articles which evaluated the impact of various exposure factors. All searches used the term, "traffic related air pollution" along with a combination of key words. For the impact of the environment the following terms were used, meteorological impact, rainfall, temperature, seasonal variations, street vegetation, trees, building height, street canyon, urban street configuration and urban design. A total of 814 results were found and these were limited to articles published in the last 5 years which reduced the number to 639 . The search was further refined to relevant topics reducing the number to 240 . After reviewing the abstracts a total of 27 articles met the inclusion criteria. 


\section{Results and discussion}

\subsection{Health impact of traffic related air pollution}

There are varying degrees of consistency in relation to the evidence on the health effects associated with traffic related air pollution. The following information aims to clarify the current evidence available on the health impact of traffic related air pollution.

\subsubsection{Respiratory illnesses}

Research exploring the link between respiratory illnesses and traffic related air pollution has been completed in numerous countries with varying outcomes. Traffic derived particulate matter and nitrogen dioxide have been associated with a range of respiratory illnesses which are outlined below.

Short term exposure to traffic related air pollution has been linked to the exacerbation of asthma symptoms [4-6]. A meta-analysis found increasing evidence that long term exposure to traffic related air pollution can contribute to the development of new onset asthma in both children and adults [4].

An association between exposure to particulate matter and the development of lung cancer was found in a study which looked at the impact of traffic related air pollution in nine European countries [7]. This research found no association between the level of nitrogen dioxide and lung cancer however link was evidenced by a study carried out in Japan [8].

Of the papers reviewed in relation to respiratory problems, six $[6,9-12]$ focused on the impact of traffic related air pollution on children. Children are often the focus of research as they can be more vulnerable to air pollution. Their lungs and immune systems are not completely developed $[4,13]$, they inhale a higher dose of airborne particles in relation to their size compared with adults $[4,6,9]$ and may spend more time outdoors $[4,11]$. Children exposed to nitrogen dioxide within their first year are at an increased risk of developing a persistent cough and wheezing $[10,13]$.

\subsubsection{Cardiovascular illnesses}

The evidence found within this literature search indicates a link between traffic related air pollution and various cardiovascular illnesses. There is strong evidence that diesel exhaust emissions promote changes in atherosclerotic plaques which can lead to cardiovascular problems such as stroke or heart disease. This research was completed using experimental mice and identified the negative impact of diesel exhaust fumes on biological mechanisms [14]. Several other studies found an increase in mortality due to cardiac function by using a land use regression models [15-17]. Furthermore, a positive association was found between exposure to both nitrogen dioxide and particulate matter and the incidence of stroke $[8,18]$. In addition, a meta-analysis found significance between exposure to nitrogen dioxide and particulate matter and the increase of hospital admissions for cardiovascular illnesses [19]. 


\subsubsection{Air pollution and pregnancy}

Exposure to traffic related air pollution can impact both the pregnant woman and the foetus. Exposure to nitrogen dioxide during the entire pregnancy has been associated with a risk of pregnant woman developing pre-eclampsia $[20,21]$. Furthermore proximity to a major road has also been associated with pre -term birth $[21,22]$. Conflicting evidence has been found between birth weight and exposure to traffic related air pollution [23-27]. Several studies which modelled prenatal exposure found a reduction in birth weight $[23,24,26]$ however two studies negated the association $[25,27]$. Due to the lack of clarity and the methodology short comings of some studies $[20-24,26]$ there is a need for additional evidence on the subject of air pollution and pregnancy.

\subsubsection{Additional health effects}

Increasing levels of traffic have been associated with rises in total health risk and natural mortality $[28,29]$. A study found an association between exposure to nitrogen dioxide and particulate matter and autism spectrum disorders. However this research did not take into consideration the impact which noise and other nuisances associated with heavy traffic areas could have on the development of autism therefore the strength of the evidence should be evaluated [30].

Research has also been completed regarding a link between air pollution and diabetes, however the results are inconsistent. One study suggested both nitrogen dioxide and particulate matter are linked to diabetes [31]. This study used estimates of home outdoor levels. This may not be representative of the levels of pollutants which people are exposed too therefore the results should be viewed with caution. Another similar study found inconclusive evidence regarding a link to diabetes [32]. Another health effect found was a reduction in fertility rates associated with particulate matter. The research completed was based on previous studies such as Veras et al. [33] using mice which found a reduction in fertility rates. The research completed used land regression modelling to identify if the results found in mice where transferrable to humans [34]. Several studies were also completed assessing the link between allergic sensitisation and traffic related air pollution, however no associations were found $[35,36]$.

\subsection{Environmental factors}

The local environment can impact upon the dispersion rate of traffic related air pollution. There are various factors which can increase and decrease the levels. Much of the evidence from these studies can be site specific therefore must be fully evaluated before applying to other areas.

\subsubsection{Meteorological impact}

Wind, temperature and rainfall can all impact on the levels of pollutants which people are exposed to. Wind direction and wind speed can be influential on levels of air pollution by increasing or decreasing the rate and area of dispersion [3746]. Calm conditions are generally associated with higher levels of air pollution $[40,41,43,44,46]$. Several studies which consider wind speed and direction as contributing factors for levels of air pollution, use wind tunnels to establish the 
impact [41, 44]. The results from wind tunnel studies should be viewed with caution as they may over or under estimate real world conditions. Furthermore meteorology is affected by the buildings in an area which can cause turbulence and disrupt air flow [47].

Rainfall has been found to reduce the levels of traffic related air pollution [39, $46,48]$. Cool, wet days are found to have fewer exceedances of air quality objectives [48]. Increased rain washes deposited particles from the leaves of trees, increasing the ability of stomata to absorb pollutants [46].

Temperature is another factor which can impact upon the formation and dispersion of air pollution. During periods of warm weather, increasing air pollution levels have been found [48-50]. Furthermore, heat waves have been associated with exceedances in air quality objectives [49]. One study states the reason for exceedances during warm weather is that mid-latitude cyclone frequencies decrease [48]. Conflicting evidence was found, which states, warm weather can cause greater dispersion and dilution of pollutants therefore reducing air pollution levels [42]. One study found that temperature has a greater impact on the levels of particulate matter compared to nitrogen dioxide [43].

Although warm temperatures are associated higher pollution levels, the majority of evidence is in agreement that levels of air pollution are highest in the winter and decrease in the summer [40-44, 51].

\subsubsection{Built environment impact}

The built environment consists of land use patterns, transport networks and the arrangement of buildings. The design of the built environment can positively or negatively impact on the levels of air pollution [52].

Street canyons are frequently used in research to understand the impact of the built environment on air pollution levels. They are characterised by having tall buildings on both sides of the street therefore creating a canyon effect [53]. This can impact air pollution by restricting the mixing of air and lowering the dispersion potential $[47,53,54]$. This restriction of air flow can result in higher levels of air pollution including nitrogen dioxide and particulate matter $[47,53]$. The exact impact of the street canyon will depend on local factors including the permeability of the street canyon [54] and building height [47, 55].

Research revealed that traffic calming measures do not reduce the levels of nitrogen dioxide, in fact one study found that speed ramps caused an increase in levels [44]. This is due to the increase in acceleration and deceleration [44]. Reducing the speed limit was the only measure found to significantly reduce the levels of air pollution [56].

Roadside noise barriers are now a more common feature of major roads and can impact on the roadside levels of traffic related air pollution [57]. Several studies have found that barriers can reduce the levels of roadside pollutants [57, 58]. However one study found that this reduction is dependent on the wind direction [57]. Barriers can vary in their height, width and distance from the road, which are all factors that can impact upon their effectiveness in reducing levels of traffic related air pollution. 


\subsubsection{Impact of roadside vegetation}

The impact which trees can have on the levels of traffic related air pollution is complex and the evidence regarding their ability to reduce air pollution levels is variable. There are numerous factors which should be considered when assessing their impact including the tree height, width, size of canopy and type of tree [38]. Several studies have found the presence of trees to cause an increase in levels of both particulate matter and nitrogen dioxide [45, 59-61]. The tree canopy may cause pollutants to become trapped by reducing ventilation $[45,59,60]$. This indicates that the trees have a greater ability to reduce dispersion rates than filter pollutants therefore causing pollutant levels to increase.

The evidence in relation to the impact of trees is inconsistent as there are a number of studies which state that trees reduce the levels of air pollution $[38,46$, $62,63]$. Trees can act as a barrier between the source (traffic) and the public therefore reducing personal exposure [38]. Furthermore, the stomata absorbs pollutants and particles are removed from the air by deposition onto leaves and branches [60]. One study suggested that deciduous trees should be planted. These trees would lose their leaves in winter, which is the season when levels are highest. The reduction in the tree canopy allows air to flow encouraging the dispersion of pollutants [59].

The impact which trees can have is also influenced by their location. Trees within a street canyon can have less of an impact than those beside an open road [38]. Research has indicated that trees should be planted far away from the pollution source [60] and be a triangular shape [38] to reduce the levels of traffic related air pollution. It is evident that assessing the impact of trees is complex and various factors need to be taken into consideration.

\section{Conclusion}

The literature review indicated that there is a link between exposure to traffic related air pollution and health effects, however the evidence is inconsistent. The strongest evidence found was the association between traffic relation air pollution and the development of atherosclerotic plaques. Numerous other health effects have been investigated with various quality of evidence. Additional rigorous research is needed to establish causation. Furthermore, evidence regarding individual pollutants is limited as people are exposed to a mixture of air pollutants therefore it is often difficult to determine the specific impact.

From the review of literature completed it is clear that the levels of traffic related air pollution are affected by various environmental factors. Studies have investigated a wide range of factors such as weather, seasons, street canyons, road design and roadside vegetation. Due to the number of these factors, each spatial and temporal location is unique, making traffic related air pollution estimates difficult to establish. Furthermore, the majority of research considered these factors separately thus their synergistic interactions are unclear. There is a lack of quantitative evidence that could inform which intervention would be most successful in reducing air pollution and specific pollutants. 
The evidence reviewed highlighted numerous methodological limitations. A number of studies used land use regression models or other modelling techniques to consider the impact on health, other methodologies used available data sets or completed meta-analyses. These techniques aren't suitable to establish definite causation. Some studies investigating environmental factors used experimental conditions under or over estimating real life conditions. Only few methodologies using measured air pollution levels and case control studies provide stronger evidence.

Although much research has been completed in relation to the impact of traffic related air pollution, gaps in knowledge still remain. The main research gaps highlighted by this review are:

- the lack of causal evidence between traffic related air pollution and health

- the lack of comprehensive studies examining how features of the environment impact traffic related air pollution

In addition, few pieces of research included both health impact and environmental factor. Research should consider all these factors as they interact to form personal exposure levels. Often research assumes that each person in an area has the same level of exposure by using data from an air quality monitoring station. This approach could lead to errors as it does not take into considerations features of the environment highlighted to contribute to traffic related air pollution.

The findings of this review will inform the design of future work. The use of monitored traffic related air pollution data in case-study settings may be a way to investigate the relationship between traffic related air pollution, health impact and environmental factors.

\section{References}

[1] World Health Organisation, Ambient (Outdoor) Air Quality and Health. Denmark. 2014.

[2] European Environment Agency, Air Quality in Europe. Luxembourg 2013.

[3] Environmental Audit Committee, The Costs of poor air quality. United Kingdom. 2010.

[4] Guarnieri, M. \& Balmes, J.R. Outdoor air pollution and asthma. The Lancet, 383 (9928), 1581-1592. 2014.

[5] Zhou, C., Baïz, N., Banerjee, S., Charpin, D.A., Caillaud, D., de Blay, F., Raherison, C., Lavaud, F. and Annesi-Maesano, I. The relationships between ambient air pollutants and childhood asthma and eczema are modified by emotion and conduct problems. Annals of Epidemiology, 23 (12), 778-783. 2013.

[6] Gasana, J., Dillikar, D., Mendy, A., Forno, E. and Ramos Vieira, E. Motor vehicle air pollution and asthma in children: A meta-analysis. Environmental research, 117, 36-45. 2012.

[7] Raaschou-Nielsen, O., Andersen, Z.J., Beelen, R., Samoli, E., Stafoggia, M., Weinmayr, G., Hoffmann, B., Fischer, P., Nieuwenhuijsen, M.J., Brunekreef, B., Xun, W.W., Katsouyanni, K., Dimakopoulou, K., Sommar, J., (2013) Air pollution and lung cancer incidence in 17 European cohorts: 
prospective analyses from the European Study of Cohorts for Air Pollution Effects (ESCAPE). The Lancet Oncology, 14 (9), 813-822.

[8] Yorifuji, T., Kashima, S., Tsuda, T., Ishikawa-Takata, K., Ohta, T., Tsuruta, $\mathrm{K}$. and Doi, H. Long-term exposure to traffic-related air pollution and the risk of death from hemorrhagic stroke and lung cancer in Shizuoka, Japan. Science of The Total Environment, 443 (0), 397-402. 2013.

[9] Buonanno, G., Marks, G.B. and Morawska, L. Health effects of daily airborne particle dose in children: Direct association between personal dose and respiratory health effects. Environmental Pollution, 180 (0), 246-250. 2013.

[10] Kim, B., Lee, S., Kwon, J., Jung, Y., Lee, E., Yang, S.I., Kim, H., Seo, J., Kim, H., Kim, H., Leem, J., Kwon, H. and Hong, S. Traffic-related air pollution is associated with airway hyper-responsiveness. Journal of Allergy and Clinical Immunology, 133 (6), 1763-1765. 2014.

[11] Lee, Y.L., Wang, W., Lu, C., Lin, Y. and Hwang, B. Effects of ambient air pollution on pulmonary function among schoolchildren. International journal of hygiene and environmental health, 214 (5), 369-375. 2011.

[12] Brugha, R. and Grigg, J. Urban Air Pollution and Respiratory Infections. Paediatric Respiratory Reviews, 15 (2), 194-199. 2014.

[13] Esplugues, A., Ballester, F., Estarlich, M., Llop, S., Fuentes-Leonarte, V., Mantilla, E., Vioque, J. and Iñiguez, C. Outdoor, but not indoor, nitrogen dioxide exposure is associated with persistent cough during the first year of life. Science of The Total Environment, 409 (22), 4667-4673. 2011.

[14] Bai, N., Kido, T., Suzuki, H., Yang, G., Kavanagh, T.J., Kaufman, J.D., Rosenfeld, M.E., van Breemen, C. and Eeden, S.F.v. (2011) Changes in atherosclerotic plaques induced by inhalation of diesel exhaust. Atherosclerosis, 216 (2), 299-306. 2011.

[15] Wu, S., Deng, F., Liu, Y., Shima, M., Niu, J., Huang, Q. and Guo, X. Temperature, traffic-related air pollution, and heart rate variability in a panel of healthy adults. Environmental research, 120 (0), 82-89. 2013.

[16] Tsai, D., Wang, J., Chuang, K. and Chan, C. Traffic-related air pollution and cardiovascular mortality in central Taiwan. Science of The Total Environment, 408 (8), 1818-1823. 2010.

[17] Maté, T., Guaita, R., Pichiule, M., Linares, C. and Díaz, J. Short-term effect of fine particulate matter (PM2.5) on daily mortality due to diseases of the circulatory system in Madrid (Spain). Science of The Total Environment, 408 (23), 5750-5757. 2010.

[18] Katsoulis, M., Dimakopoulou, K., Pedeli, X., Trichopoulos, D., Gryparis, A., Trichopoulou, A. and Katsouyanni, K. Long-term exposure to trafficrelated air pollution and cardiovascular health in a Greek cohort study. Science of The Total Environment, 490 (0), 934-940. 2014.

[19] Sicard, P., Lesne, O., Alexandre, N., Mangin, A. and Collomp, R. Air quality trends and potential health effects - Development of an aggregate risk index. Atmospheric Environment, 45 (5), 1145-1153. 2011. 
[20] Hu, H., Ha, S., Roth, J., Kearney, G., Talbott, E.O. and Xu, X. Ambient air pollution and hypertensive disorders of pregnancy: A systematic review and meta-analysis. Atmospheric Environment, 97 (0), 336-345. 2014.

[21] Yorifuji, T., Naruse, H., Kashima, S., Murakoshi, T. and Doi, H. Residential proximity to major roads and obstetrical complications. Science of The Total Environment, 508 (0), 188-192. 2015.

[22] Padula, A.M., Mortimer, K.M., Tager, I.B., Hammond, S.K., Lurmann, F.W., Yang, W., Stevenson, D.K. and Shaw, G.M. Traffic-related air pollution and risk of preterm birth in the San Joaquin Valley of California. Annals of Epidemiology, 24 (12), 888-895. 2014.

[23] Lakshmanan, A., Chiu, Y.M., Coull, B.A., Just, A.C., Maxwell, S.L., Schwartz, J., Gryparis, A., Kloog, I., Wright, R.J. and Wright, R.O. Associations between prenatal traffic-related air pollution exposure and birth weight: Modification by sex and maternal pre-pregnancy body mass index. Environmental research, 137 (0), 268-277. 2015.

[24] Amegah, A.K. and Jaakkola, J.J.K. Work as a street vendor, associated traffic-related air pollution exposures and risk of adverse pregnancy outcomes in Accra, Ghana. International journal of hygiene and environmental health, 217 (2), 354-362. 2014.

[25] Kashima, S., Naruse, H., Yorifuji, T., Ohki, S., Murakoshi, T., Takao, S., Tsuda, T. and Doi, H. Residential proximity to heavy traffic and birth weight in Shizuoka, Japan. Environmental research, 111 (3), 377-387. 2011.

[26] Pedersen, M., Giorgis-Allemand, L., Bernard, C., Aguilera, I., Andersen, A.N., Ballester, F., Beelen, R.M.J., Chatzi, L. Ambient air pollution and low birthweight: a European cohort study (ESCAPE). The Lancet Respiratory Medicine, 1 (9), 695-704. 2013.

[27] Gehring, U., Wijga, A.H., Fischer, P., de Jongste, J.C., Kerkhof, M., Koppelman, G.H., Smit, H.A. and Brunekreef, B. Traffic-related air pollution, preterm birth and term birth weight in the PIAMA birth cohort study. Environmental research, 111 (1), 125-135. 2011.

[28] Zhang, K. and Batterman, S. Air pollution and health risks due to vehicle traffic. Science of The Total Environment, 450-451, 307-316. 2013.

[29] Beelen, R., Raaschou-Nielsen, O., Stafoggia, M., Andersen, Z.J., Weinmayr, G., Hoffmann, B., Wolf, K., Samoli, E. Effects of long-term exposure to air pollution on natural-cause mortality: an analysis of 22 European cohorts within the multicentre ESCAPE project. The Lancet, 383 (9919), 785-795. 2014.

[30] Kalkbrenner, A.E., Schmidt, R.J. and Penlesky, A.C. Environmental Chemical Exposures and Autism Spectrum Disorders: A Review of the Epidemiological Evidence. Current Problems in Pediatric and Adolescent Health Care, 44 (10), 277-318. 2014.

[31] Eze, I.C., Schaffner, E., Fischer, E., Schikowski, T., Adam, M., Imboden, M., Tsai, M., Carballo, D., von Eckardstein, A., Künzli, N., Schindler, C. and Probst-Hensch, N. Long-term air pollution exposure and diabetes in a 
population-based Swiss cohort. Environment international, 70, 95-105. 2014.

[32] Balti, E.V., Echouffo-Tcheugui, J.B., Yako, Y.Y. and Kengne, A.P. Air pollution and risk of type 2 diabetes mellitus: A systematic review and metaanalysis. Diabetes research and clinical practice, 106 (2), 161-172. 2014.

[33] Veras, M., Damaceno-Rodrigues, R., Guimaraes Silva, J., Saldiva, E. Chronic Exposure to fine particulate matter emitted by traffic affects reproductive and foetal outcomes in mice. Environmental Research, 109 (5), 536-543. 2009.

[34] Nieuwenhuijsen, M.J., Basagaña, X., Dadvand, P., Martinez, D., Cirach, M., Beelen, R. and Jacquemin, B. Air pollution and human fertility rates. Environment international, 70, 9-14. 2014.

[35] Gruzieva, O., Gehring, U., Aalberse, R., Agius, R., Beelen, R., Behrendt, H., Bellander, T., Birk, M., de Jongste, J.C. Meta-analysis of air pollution exposure association with allergic sensitization in European birth cohorts. Journal of Allergy and Clinical Immunology, 133 (3), 767-776. 2014.

[36] Gruzieva, O., Bellander, T., Eneroth, K., Kull, I., Melén, E., Nordling, E., van Hage, M., Wickman, M., Moskalenko, V., Hulchiy, O. and Pershagen, G. Traffic-related air pollution and development of allergic sensitization in children during the first 8 years of life. Journal of Allergy and Clinical Immunology, 129 (1), 240-246. 2012.

[37] Venkatram, A., Snyder, M., Isakov, V. and Kimbrough, S. Impact of wind direction on near-road pollutant concentrations. Atmospheric Environment, 80, 248-258. 2013.

[38] Brantley, H.L., Hagler, G.S.W., J. Deshmukh, P. and Baldauf, R.W. Field assessment of the effects of roadside vegetation on near-road black carbon and particulate matter. Science of The Total Environment, 468-469, 120129. 2014.

[39] Aurangojeb, M. Relationship between PM10, NO2 and particle number concentration: validity of air quality controls. Procedia Environmental Sciences, 6, 60-69. 2011.

[40] Russo, A., Trigo, R.M., Martins, H. and Mendes, M.T. NO2, PM10 and O3 urban concentrations and its association with circulation weather types in Portugal. Atmospheric Environment, 89 (0), 768-785. 2014.

[41] Unal, Y.S., Toros, H., Deniz, A. and Incecik, S. Influence of meteorological factors and emission sources on spatial and temporal variations of PM10 concentrations in Istanbul metropolitan area. Atmospheric Environment, 45 (31), 5504-5513. 2011.

[42] Li, L., Qian, J., Ou, C., Zhou, Y., Guo, C. and Guo, Y. Spatial and temporal analysis of Air Pollution Index and its timescale-dependent relationship with meteorological factors in Guangzhou, China, 2001-2011. Environmental Pollution, 190 (0), 75-81. 2014.

[43] Patton, A.P., Perkins, J., Zamore, W., Levy, J.I., Brugge, D. and Durant, J.L. Spatial and temporal differences in traffic-related air pollution in three urban neighborhoods near an interstate highway. Atmospheric Environment, 99 (0), 309-321. 2014. 
[44] Ghafghazi, G. and Hatzopoulou, M. (2015) Simulating the air quality impacts of traffic calming schemes in a dense urban neighborhood. Transportation Research Part D: Transport and Environment, 35 (0), 11 22. 2015.

[45] Gromke, C. and Blocken, B. Influence of avenue-trees on air quality at the urban neighborhood scale. Part II: Traffic pollutant concentrations at pedestrian level. Environmental Pollution, 196 (0), 176-184. 2015.

[46] Nowak, D.J., Hirabayashi, S., Bodine, A. and Hoehn, R. Modeled PM2.5 removal by trees in ten U.S. cities and associated health effects. Environmental Pollution, 178 (0), 395-402. 2013.

[47] Eeftens, M., Beekhuizen, J., Beelen, R., Wang, M., Vermeulen, R., Brunekreef, B., Huss, A. and Hoek, G. Quantifying urban street configuration for improvements in air pollution models. Atmospheric Environment, 72 (0), 1-9. 2013.

[48] Ramsey, N.R., Klein, P.M. and Moore III, B. The impact of meteorological parameters on urban air quality. Atmospheric Environment, 86 (0), 58-67. 2014

[49] Papanastasiou, D.K., Melas, D. and Kambezidis, H.D. Air quality and thermal comfort levels under extreme hot weather. Atmospheric Research, 152 (0), 4-13. 2015.

[50] Vanos, J.K., Cakmak, S., Bristow, C., Brion, V., Tremblay, N., Martin, S.L. and Sheridan, S.S. Synoptic weather typing applied to air pollution mortality among the elderly in 10 Canadian cities. Environmental research, 126 (0), 66-75. 2013.

[51] Chen, R., Peng, R.D., Meng, X., Zhou, Z., Chen, B. and Kan, H. Seasonal variation in the acute effect of particulate air pollution on mortality in the China Air Pollution and Health Effects Study (CAPES). Science of The Total Environment, 450-451 (0), 259-265. 2013.

[52] Lawrence, F., Health and the Built Environment: A Review. Canada. 2012.

[53] Rakowska, A., Wong, K.C., Townsend, T., Chan, K.L., Westerdahl, D., Ng, S., Močnik, G., Drinovec, L. and Ning, Z. Impact of traffic volume and composition on the air quality and pedestrian exposure in urban street canyon. Atmospheric Environment, 98 (0), 260-270. 2014.

[54] Yuan, C., Ng, E. and Norford, L.K. Improving air quality in high-density cities by understanding the relationship between air pollutant dispersion and urban morphologies. Building and Environment, 71 (0), 245-258. 2014.

[55] Weichenthal, S., Farrell, W., Goldberg, M., Joseph, L. and Hatzopoulou, M. Characterizing the impact of traffic and the built environment on near-road ultrafine particle and black carbon concentrations. Environmental research, 132 (0), 305-310. 2014.

[56] Lefebvre, W., Fierens, F., Trimpeneers, E., Janssen, S., Van de Vel, K., Deutsch, F., Viaene, P., Vankerkom, J., Dumont, G., Vanpoucke, C., Mensink, C., Peelaerts, W. and Vliegen, J. Modeling the effects of a speed limit reduction on traffic-related elemental carbon (EC) concentrations and population exposure to EC. Atmospheric Environment, 45 (1), 197-207. 2011. 
[57] Hagler, G.S.W., Tang, W., Freeman, M.J., Heist, D.K., Perry, S.G. and Vette, A.F. Model evaluation of roadside barrier impact on near-road air pollution. Atmospheric Environment, 45 (15), 2522-2530. 2011.

[58] Hagler, G.S.W., Lin, M., Khlystov, A., Baldauf, R.W., Isakov, V., Faircloth, J. and Jackson, L.E. Field investigation of roadside vegetative and structural barrier impact on near-road ultrafine particle concentrations under a variety of wind conditions. Science of The Total Environment, 419 (0), 7-15. 2012.

[59] Jin, S., Guo, J., Wheeler, S., Kan, L. and Che, S. Evaluation of impacts of trees on PM2.5 dispersion in urban streets. Atmospheric Environment, 99 (0), 277-287. 2014.

[60] Vos, P.E.J., Maiheu, B., Vankerkom, J. Improving local air quality in cities: To tree or not to tree? Environmental Pollution, 183 (0), 113-122. 2013.

[61] Janhäll, S. Review on urban vegetation and particle air pollution Deposition and dispersion. Atmospheric Environment, 105 (0), 130-137. 2015.

[62] Tallis, M., Taylor, G., Sinnett, D. and Freer-Smith, P. Estimating the removal of atmospheric particulate pollution by the urban tree canopy of London, under current and future environments. Landscape and Urban Planning, 103 (2), 129-138. 2011.

[63] Vailshery, L.S., Jaganmohan, M. and Nagendra, H. Effect of street trees on microclimate and air pollution in a tropical city. Urban Forestry \& Urban Greening, 12 (3), 408-415. 2013. 